\title{
Orlando, ou a tendência social da androginia
}

\author{
NÍZIA MARIA ALVARENGA
}

RESUMO: Este artigo analisa o filme Orlando por ser expressão de uma das tendências que vêm despontando no processo atual de mudanças sociais no conjunto das sociedades capitalistas ocidentais. A dimensão simbólica destas sociedades abrange representações tais como racionalidade, objetividade, pragmatismo, impessoalidade, utilitarismo, disciplina e neutralidade afetiva, que constituem o cerne do sistema de valores sociais predominantes. Uma alteração desta dimensão significa uma revolução em seu modo de ser social. Orlando sugere uma reconciliação entre razão, sensibilidade, emoções, sentimentos e fantasia, abrindo espaço para uma sociedade andrógina, presidida pelo princípio erótico. A dinâmica produtivista do capitalismo é substituída por uma forma de sociabilidade marcada pela amorosidade e o desfrute da vida.

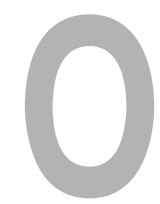

ponto de partida desta análise é o entendimento de que a civilização ocidental contemporânea atravessa uma crise que deve desdobrarse na emergência de formas sociais novas, dentre as quais o cultural é um campo privilegiado de análise. Nesta perspectiva rastreia-se, no universo cinematográfico, as tendências que estão se delineando atualmente no processo de mudanças sociais em curso no conjunto das sociedades capitalistas ocidentais.

As diversas análises críticas da sociedade industrial capitalista, desde os frankfurtianos, abordam os mais variados aspectos da organização social e do desenvolvimento assentados na razão. Com Adorno e Horkheimer temos a conhecida reflexão em torno da dialética da civilização e da transformação da razão emancipadora em razão instrumental. Estreitamente vinculada à ascensão hegemônica da razão instrumental, embutida no projeto iluminista de desencantamento do mundo, constituiu-se uma dimensão simbólica que abrange

Professora do Departamento de Ciências Sociais da Universidade Federal de Uberlândia

UNITERMOS: mudança social, capitalismo, valores sociais, androginia. 
1 De acordo com a teoria freudiana, referemse ao impulso de vida e ao impulso de morte, respectivamente. significações imaginárias sociais tais como racionalidade, objetividade, pragmatismo, impessoalidade, utilitarismo, disciplina e neutralidade afetiva, produtos da extensão, a cada uma destas formações sociais, da produção capitalista industrial assentada em uma organização empresarial nos termos expostos por Weber, a saber, de uma administração racional, de um direito racional e de uma contabilidade racional. Tais significações constituem um núcleo de valores que norteiam a ação social. Uma alteração desse núcleo implica uma revolução em seu modo de ser social.

Na dinâmica do progresso da sociedade industrial capitalista, sustentada pela razão instrumental, o jogo entre Eros e Thanatos ${ }^{1}$ privilegiou a expressão das forças agressivas em detrimento do primeiro. A tentativa de superar a angústia e o medo frente ao desconhecido, pela via do conhecimento, conduziu o desenvolvimento social a uma negação e uma repressão cada vez mais radicais dos componentes emocionais, afetivos e sensíveis da condição humana. Em um único e mesmo processo, o impulso erótico, vital, de organização livre da satisfação foi subjugado e a razão foi erigida como a função por excelência do gênero humano. O aprofundamento do processo de separação entre paixão e razão significou a desvalorização de tudo o que está ligado aos sentidos e à sua satisfação: o conhecimento proporcionado pelos órgãos dos sentidos foi invalidado e estes entraram em desuso. A razão positivista cada vez mais marginalizou o amor e adentrou o terreno pantanoso da racionalidade instrumental, liberando as paixões destrutivas, configurando o que Rouanet (1988) chamou de razão louca.

A tensão entre tendências opostas, constitutiva de toda ordem social, permite pensar a possibilidade de emergência de uma alternativa vital, contraposta à cultura de morte do capitalismo. A erotização da vida social, em suas várias dimensões, configura-se em um meio de balizar as práticas sociais de sujeitos individuais e coletivos capazes de, no seu fazer histórico, inventar relações sociais de caráter libertador, em consonância com o princípio de vida. Eros, enquanto impulso vital, é força geradora, capaz de, no exercício da livre fantasia, levar à invenção do não experimentado. Deparamo-nos aqui com o Eros criador de cultura, o impulso vital que, associado ao Logos, poderia dar origem a uma ordem social não repressiva, a uma sociedade que incorpora a esfera dos sentimentos, da afetividade e da imaginação como parte intrínseca à vida e com estatuto equivalente ao da razão, isto é, à sociedade andrógina. A noção de androginia, com a qual lidamos, refere-se à busca da unidade interior ao nível psíquico, à integração dos componentes masculinos e femininos presentes em cada indivíduo; a androginia seria a recuperação da dimensão sensível, sensual, emocional e da fantasia aniquiladas no processo de constituição do sujeito racional da civilização industrial.

O mito do andrógino de Platão é sugestivo do poder capaz de impulsionar o homem a rebelar-se contra a autoridade. $\mathrm{O}$ andrógino, contendo o masculino e o feminino, é inteiriço, de invulgar força e vigor. Porém, dada sua vitalidade, insurgiram contra os deuses, e estes, para dominá-los, recorreram 
ao expediente de dividí-los em dois para assim quebrar sua força. O processo de fragmentação é fundamental na consolidação e manutenção da dominação. Desde então os homens tornaram-se mais úteis para os deuses, mais fracos e carentes, buscando incessantemente sua outra metade. E Aristófanes ainda diz que o amor é o desejo que impele o homem nesta busca, a força capaz de redimí-lo.

Em termos sociais, a androginia seria uma organização da vida coletiva que, sem abrir mão de sua atual capacidade produtiva, do conhecimento acumulado, da tecnologia disponível e potencial, de sua iniciativa e força de realização, balizaria tudo isso com valores oriundos dos sentimentos, da solidariedade e cooperação, atribuindo outro significado ao ato de produzir bens materiais e espirituais. Seria, pela instituição de outro imaginário social, a recuperação do sentido da vida perdido no processo de desencantamento do mundo pelo conhecimento positivo da natureza.

Dentre as tendências mais visíveis que despontam, privilegiamos a análise da que aponta para uma reconciliação entre razão, sensibilidade, emoções, sentimentos e fantasia, dando lugar a uma sociedade andrógina, presidida pelo princípio erótico. O universo de análise escolhido é o cinema, por suas características intrínsecas de internacionalismo e de diálogo com as questões cruciais do movimento social.

Orlando é um filme que liberta a alma dos liames do instituído, onde a imaginação alça seu vôo sem fronteiras e subverte o mundo das significações instituídas no sentido acima apontado.

A narrativa, uma adaptação livre da novela homônima de Virginia Woolf, é uma construção metafórica que se sustenta na imaginação e expressase por meio de figurações diversas. Orlando pode ser tomado como uma alegoria do tempo histórico, o acontecer de um período da civilização ocidental que abrange 400 anos, desde a rainha Isabel, na Inglaterra, até nossos dias. É um jovem nobre, pertencente à mais alta estirpe da aristocracia inglesa. A partir de um comprometimento relativo e ambíguo com a ordem, encarna a tendência alternativa e crítica deste processo social. Este traço alternativo concretiza-se numa tendência andrógina que se manifesta em uma inadaptação e relativa marginalidade, desde o começo. A androginia é a camada mais visível da conotação alegórica do personagem.

Entretanto esta condição andrógina só será referida explicitamente ao final. A conotação alegórica do personagem é construída ao longo do filme, diretamente por meio do personagem de Orlando, que exprime cada momento histórico em seu modo de ser, e também, indiretamente, mediante os demais personagens que, além de conotarem aspectos da ordem social não presentes em Orlando, criam um contraponto para a oposição referencial de seus atos. No transcurso da narrativa o personagem vai expressando os papéis sociais correspondentes ao sexo que encarna, de acordo com cada época. $\mathrm{O}$ caráter processual da androginia apresenta-se no confronto com os valores vigentes, e ela apenas será assumida quando, depois de uma longa experiência, 
400 anos, em condições históricas diversas e na qualidade de homem, primeiro, e então mulher, constata a insuficiência de ambas.

O traço forte do personagem é seu sentido de autopreservação, sua capacidade de resistência aos imperativos da ordem social para sacrificar parte de suas potencialidades, enfim, um exercício constante de autonomia. Em nenhum momento abdica de sua unidade e de sua ligação com a natureza. Ao contrário, as frustrações que sofre em seus relacionamentos sociais, de ordem amorosa, fraterna ou profissional, levam-no a refugiar-se no campo e consolidar os laços íntimos com a natureza.

O perfil de cada momento histórico, neste interregno, se exprime por meio do personagem e das situações sociais vividas por ele. $\mathrm{O}$ século XV é um século de transição. Já havia sido detonado o rosário das grandes invenções e descobrimentos, e das novas idéias que impulsionaram o processo de mudanças que culminou na ordem social capitalista. Entretanto os contornos da nova ordem apenas se desenhavam em termos de costumes e de mentalidade. A organização sociopolítica e econômica do feudalismo ainda não havia sido profundamente afetada. As primeiras partes do filme-Morte, Amor, Poesia e Política - denotam isso. O sistema de vassalagem do regime feudal continuava intacto, a propriedade definitiva do palácio onde residia Orlando foi uma concessão da rainha Isabel a este, que havia se convertido em seu favorito.

A experiência amorosa se dá nos termos do amor cortês, de sentimentos elevados, e a traição feminina leva-o a buscar refúgio na poesia. Eé a poesia que vai restabelecer seu vínculo social quando, depois de meditar acerca dos valores materiais e espirituais, inclina-se definitivamente pelos segundos.

Na tentativa de ingressar no reino das artes, por meio da poesia, procura contato com um poeta. Aqui já se delineia o espírito da época que emerge. A relação com o poeta é um desastre. Este mostra-se um interesseiro, arrogante e vaidoso, que orienta suas ações pelas vantagens que possa obter. Em uma de suas falas já anuncia o refrão capitalista: "Tempo é dinheiro". Conforme aponta Tönnies (cf. 1979) em sua análise da Kürwille, o homem só age no sentido de obter vantagem e as trocas encerram sempre um ganho adicional: o poeta só se dispõe a ler os escritos de Orlando quando este lhe garante o pagamento anual solicitado, concretizando uma relação de mecenato. Entretanto a relação social por excelência, no sentido weberiano, de racionalidade adequada a fins, ainda não se configura, os personagens movemse, prioritariamente, no campo da ação social racional adequada a valores. A relação de dependência econômica não impede o poeta de publicar uma ácida crítica a este nobre, em sua opinião vulgar, com pretensões artísticas. Tampouco leva Orlando a romper um compromisso moral de pagar a pensão anual.

Nessas três primeiras partes - Morte, Amor e Poesia - o personagem se mostra um homem mais preocupado com os sentimentos nobres e pouco dado a realizações de caráter prático e/ou produtivo. A figura lânguida com matizes melancólicos que passeia pelo campo e se recosta ao pé de um 
frondoso carvalho enuncia o caráter do personagem nestas seções.

O século XVIII, que se inicia, encontra-o com a disposição de exercitar, com mais ênfase, suas qualidades masculinas. Esta disposição se explicita nos símbolos exibidos no plano que abre a seção Política: um plano médio da parte externa de Palácio Real, cruzado por Orlando, em passo de marcha, acompanhado por um compasso militar. Dirige-se ao rei para solicitar-lhe o cargo de embaixador da Coroa em um longínquo país oriental. É a primeira aparição de Orlando ostentando um gesto cultural propriamente masculino. Até então apresentava uma postura mais suave, ainda que longe de qualquer gesto afeminado.

O desgosto com o espírito da época, que já alcançava também as artes, leva-o a um auto-exílio em um mundo onde a racionalidade não se impunha soberana a princípios éticos, estéticos e morais: vai como embaixador a um país do Oriente Médio e aí permanece por longos anos.

Exibindo as qualidades masculinas de iniciativa, capacidade intelectual, independência, e munido do que ele mesmo chama de virtudes varonis, lealdade e coragem, presta valiosos serviços à coroa britânica, que por isso o condecora. Em meio à cerimonia de condecoração estala uma guerra e se apresenta o xeque-mate para o curso do progresso dominado exclusivamente pelas qualidades masculinas da humanidade. A mortificação da sensibilidade já transformou o indivíduo social numa universalidade despojada de qualidades sensíveis. O guerreiro vai para a guerra e mata de forma impessoal, sem ódio, simplesmente cumpre um dever profissional. Esta afirmativa de Hegel (1984) encontra sua versão também em Tönnies (1979) quando este diz que o homem da Kürwille não tem amigos nem inimigos, apenas adversários. Os sentimentos de amor e ódio são qualificados pelo pensamento como coisa estranha, estorvo desprovido de razão.

Na seqüência da guerra, o duque inglês, com uma pontaria certeira, atinge um homem que cai ferido ao lado de Orlando, que se acerca para socorrê-lo e é prontamente admoestado. O diálogo é simples e direto.

Duque: - "Deixe-o!"

Orlando: - "Este homem está morrendo."

Duque: - "Não é um homem, é o inimigo!"

Este é um momento crucial no processo de desenvolvimento da civilização ocidental e que a diferencia das demais. Weber (1967), na Introdução da Ética protestante e o espírito do capitalismo, chama a atenção para esta diferença com respeito a outros povos, em diferentes épocas. Em nenhum a racionalidade tornou-se o elemento central a dar sentido à ação social. Somente no ocidente encontramos a racionalidade, isto é, a adequação de meios a fins, de modo a otimizar os resultados pretendidos, aplicada de forma sistemática e rigorosa, em todas as esferas da vida social. Em Weber, a ação social por excelência é a ação social racional adequada a fins, e esta é a que caracteriza a ordem social capitalista.

As considerações éticas e morais embutidas na ética protestante, 
cujo alcance para a instituição do espírito capitalista é o tema desta obra, se esgarçam na mesma medida em que o mundo vai se tornando cada vez mais secular, e as concepções religiosas perdem espaço na orientação efetiva da conduta social. O protestantismo ascético desempenhou um papel relevante na instituição de novas significações sociais, expressas em termos de valores e normas de conduta, de caráter religioso, que constituem a espinha dorsal do capitalismo. A idéia de profissão (Beruf) como uma missão imposta por Deus se desdobra em uma regulação estrita do trabalho, em uma rígida moral de austeridade, frugalidade, poupança e, conseqüentemente, enriquecimento, como forma de servir a Deus. Porém a idéia de trabalho incessante e enriquecimento como obrigação para a glória de Deus se perde no processo de secularização da vida social. Permanece apenas o ideal de trabalho e enriquecimento como um fim em si mesmo, ainda que destituído de sentido.

Progressivamente, o non sense da racionalidade instrumental radicaliza sua inserção social, não deixando espaço vazio nos limites do instituído, impondo ao componente alternativo da ordem social uma reação igualmente radical. Esta etapa do processo de constituição do sujeito racional implica assumir a vida presidida pela morte, seja no pólo dominante, seja no dominado. No combate original, o senhor só é senhor porque assume a morte, a morte de sua natureza interna e, por isso mesmo, ergue-se como uma consciência subordinada, subrepticiamente, ao desejo; o servo, ao não assumir a morte, por temor assume uma vida subjugada, uma morte em vida.

No filme, é esta batalha que coloca Orlando na situação limite de ter de matar. Ante a exigência de renúncia cabal à sua inteireza primeira, isto é, à sensibilidade e aos valores correspondentes a esta esfera da vida, não lhe resta outra opção que assumir plenamente o feminino. Pela segunda vez Orlando dorme por sete dias consecutivos. A primeira foi à raiz da decepção amorosa e o resultado ao despertar foi a decisão de afastar-se da convivência social, aprofundar os vínculos com a natureza e refletir acerca dos valores materiais e espirituais da cultura. Desta feita, a transformação que se processa durante o sono salta à vista: é uma mulher quem desperta. Levanta-se e, num ato simbólico que conota regeneração, lava-se. A água salpica cintilante. A simbologia da água e do número sete é muito rica. Entre seus muitos significados possíveis, a água apresenta três grandes temas, a saber, fonte de vida, meio de purificação e regeneração. Para o caso em questão parece-nos que aponta para a regeneração, assim como o número sete, entre suas muitas possibilidades, indica "o sentido de uma mudança depois de um ciclo concluído e de uma renovação positiva" (cf. Chevalier \& Gheerbrant, 1988, p. 15 e 826). A mulher refletida no espelho mostra em suas formas a força do homem e a delicadeza da mulher. Adeclaração do personagem, que se dirige diretamente ao espectador, é assertiva: Nada mudou, só o sexo. Continua o mesmo, continua preservada a tendência andrógina! Continua a luta pela autonomia!

O retorno à Inglaterra, depois de uma breve permanência entre ciganos, é o início de sua experiência como mulher e, portanto, de destaque da 
situação da mulher em uma ordem social dominada por homens. Esta seção Sociedade -, que transcorre aproximadamente entre 1750-1850, dá relevo ao lugar da mulher na ordem social, e é palco de mudanças na mentalidade dominante, de reconhecimento do estudo sistemático, da ciência positiva como a única forma legítima de produção de conhecimentos e do surgimento do Estado burguês burocrático.

Nos saraus aristocráticos que freqüenta, os discursos proferidos pelos homens são sarcásticos e diretos ao se referir à condição feminina. A mulher está condenada a viver sua menoridade.

Os atributos masculinos da psique, tais como iniciativa e capacidade intelectual, são os únicos validados socialmente e reconhecidos apenas como características próprias do gênero masculino. Às mulheres são atribuídas a fragilidade de caráter, a afetividade e a imaturidade, por si mesmas características desqualificadas no imaginário desta ordem social nascente. O estudo sistemático, a observação empírica da realidade é um trabalho adequado ao homem. A validação exclusiva das atividades úteis à produção de bens materiais e ao crescimento da riqueza se manifesta nos diálogos. As atividades artísticas só são valorizadas e reconhecidas quando entram no circuito da produção de mercadoria para fazer crescer o lucro. No mais, se reduzem a diletantismo sem sentido.

O espírito da época delineia-se cada vez mais nitidamente. A racionalidade, a objetividade, o utilitarismo, o pragmatismo, a neutralidade afetiva e a impessoalidade são as significações imaginárias sociais emergente, instituintes da nova ordem social. Estão presentes em todas as esferas da vida social. A impessoalidade não é só para matar friamente o inimigo, é também, e muito eficientemente, para tratar burocraticamente assuntos diversos. Assim vemos a atuação do emergente Estado burocrático, na conjugação do direito racional e da administração pública racional, ao lidar com a questão relativa ao sexo de Orlando e aos direitos legais no tocante às propriedades que pertenciam a Orlando-homem. A época dos favores reais ficaram no passado. Agora Orlando deve se submeter, como cidadã, à Justiça e aguardar o julgamento dos cargos que tem contra si.

Ao ser notificada por funcionários da Justiça de que poderá permanecer no palácio na qualidade de incógnita, o nobre inglês que a condecorou quando ainda era embaixador da Coroa e declarou que o homem que estava morrendo não era um homem, mas o inimigo, mais uma vez lhe apresenta uma solução prática: propõe-lhe casamento, a única saída para ela. Nesta sociedade uma mulher só, "sem pai ou marido que a guie está perdida". E por amor, é condescendente: é o único capaz de tolerar a situação de sua ambigüidade sexual.

Aceitar a proposta de casamento por conveniência seria transigir, assumir os valores sociais que atribuem à mulher uma condição subalterna $\mathrm{e}$ dependente. Mais uma vez não transige, não faz concessões. A sequiência que dá entrada ao período que começa em 1850 e chega ao presente é uma corrida, 
no labirinto do jardim, formado por ciprestes recortados em mosaicos, empreendida por Orlando, que deixa para trás seu perplexo pretendente.

A corrida, de crescente velocidade, pode ser tomada como símbolo do processo social da modernidade que imprime uma velocidade cada vez maior às mudanças e termina numa pradaria com Orlando trajando um vestido e usando um penteado indicativos de outro período histórico: o vitoriano. Orlando se lança de bruços na terra e se oferece como noiva da natureza. Mais uma vez reafirma seu indissolúvel laço com a natureza e sua persistente recusa em sucumbir aos ditames de uma ordem social agressiva à vida.

Quando sai do labirinto a revolução industrial já transformou a face do mundo. Uma locomotiva dá este testemunho. Segundo Peter Gay (1988, p. 20), o trem é a "suprema metáfora do século XIX em movimento". Quando Orlando vê o trem pela primeira vez pergunta o que é isso e seu acompanhante responde que é o futuro. Um acompanhante jovem que surgiu, repentinamente, caído ao seu lado. O diálogo irreverente e direto que estabelecem desde o princípio se desdobra em um relacionamento amoroso. Ele a acompanha à sua casa e aí permanece por algum tempo.

A importância desta passagem, em que encontra um homem e com ele vivencia uma experiência amorosa, reside nas sugestões de um novo modo de ser homem e ser mulher, de atribuir qualidades outras aos seus respectivos papéis sociais. Ela questiona o valor da liberdade conquistada nos campos de batalha, ao preço da morte. Ele assinala a estreiteza da condição da mulher, recluída em casa, dedicada aos filhos. Colocam em cheque a amplitude do espaço público para o homem e o confinamento do espaço doméstico para a mulher.

Entretanto, a afinidade que se estabelece prontamente entre eles não é uma afinidade que se desdobre na construção de algo novo. Ele é uma alegoria dos ideais da Ilustração em seus primórdios; é a América, que no período vitoriano, de acordo com Peter Gay (cf. 1988), mostra à Europa o que será seu futuro. Quando os ventos do sudoeste soprarem ele voltará para a América. Seu compromisso é com a liberdade, seu amor é pela humanidade; esta é sua resposta a uma proposta de Orlando de ter com ela um filho. Ela é um andrógino que reconhece no espírito deste século as possibilidades de expressão mais livre, porém não pode ir com ele, não podem formar um par, não são conciliáveis. Ela é um ser autônomo que não transige em termos de seus princípios constitutivos. Ele é um espírito livre, amante da liberdade, mas que não se importa a que preço esta liberdade é conquistada.

A cena seguinte nos informa ter chegado a hora da separação deste casal metafórico: a encarnação de duas tendências históricas, uma, um processo social em curso, a outra, ainda em luta por se preservar e não ser tragada pelas circunstâncias históricas. $\mathrm{O}$ vento do sudoeste chega e leva aquele homem que se dirige ao futuro, vai trabalhar para o avanço da civilização tecnológica. É o vento, um elemento que é o próprio movimento, que é utilizado para significar o compromisso deste homem ávido de movimento, de mergulho no 
desconhecido. $\mathrm{O}$ vento representa, adequadamente, a varredura de vestígios do obsoleto e a construção do mundo moderno, um mundo em permanente movimento, em velocidade crescente. Separam-se, cada um segue o seu caminho. Orlando permanece de pé, olhando-o enquanto desaparece na neblina e começa um temporal que lava os signos da época já passada. O ronco de um avião localiza Orlando no presente. O título do último episódio é sugestivo: Nascimento.

O rumo do processo social de construção da sociedade desencantada da Ilustração é sintetizado na sequiência de um campo de guerra, de desolação e morte, o qual Orlando atravessa com dificuldades, porém não sucumbe. Pelo contrário, traz em si a vida, o indício de que o processo social em curso alcançou seu limite: está grávida. A alternativa vital que se apresenta é a reprodução do ser andrógino.

Orlando é uma mulher, a definição sexual do personagem é inequívoca, o narrador, em off, afirmou no início do filme que se tratava de um homem, e no final de uma mulher. Aqui a alegoria do andrógino explicitase em um conceito que não se refere à sexualidade. Considerando os temas desenvolvidos ao longo da diégesis, parece-nos possível sugerir que a androginia mostrada no filme aproxima-se do conceito apresentado anteriormente de uma reintegração, ao nível da psique, de atributos sensíveis, emocionais, imaginativos, ditos femininos e de atributos ditos masculinos como a racionalidade, a intelecção, a iniciativa, a capacidade de realização. Esta reintegração sugere a possibilidade de Eros e os valores concernentes à vida virem a presidir o ordenamento da vida social e do indivíduo, instâncias articuladas por vínculos constitutivos de determinação recíprocas.

Uma organização social assentada no princípio da androginia social, nas condições econômicas, tecnológicas e culturais da atualidade, abre um leque de alternativas de nova articulação entre o particular e o universal. As lutas étnicas, raciais e religiosas que têm lugar hoje sugerem novas definições para a coesão social. Na modernidade do capitalismo industrial esta coesão articulou-se, fundamentalmente, a partir dos símbolos associados ao Estado-nação, hoje solapado em suas bases pelos processos de globalização econômica e mundialização da cultura. A modernidade do capitalismo industrial consolidou uma oposição entre o particular e o universal ao nível do indivíduo, das classes e das nações. Os processos sociais em curso vêm obliterando a nitidez destas dimensões, diluindo as fronteiras entre elas e exigindo esforço para a compreensão de algo que emerge, ainda escorregadio e intermitente. 
UNITERIMS: social change, capitalism, social values, androginy.
ALVARENGA, Nízia Maria. Orlando. The social tendency of androginy.Tempo Social; Rev. Sociol. USP, S. Paulo, 9(2): 155-164, october 1997.

ABSTRACT: This article analyzes the film Orlando because it is representative of one of the trends which are emerging in the actual process of social changes occurring in the west capitalist societies. The symbolic dimension of these societies comprehends representations such as rationality, objectivity, pragmatism, unpersonalty, utilitarianism, discipline and affective neutrality which constitute the nucleous of the system of predominant social values. A change of this dimension signifies a revolution on the way of social being. Orlando suggests a reconciliation between reason, sensibility, emotions, feelings and phantasy, opening place for a androgynous society presided by the erotic principle. The productive dynamic of the capitalism is substituted by a form of sociability marked by affection and enjoyment of living.

\section{Ficha técnica do filme}

Orlando - Inglaterra, 1992

Diretora: Sally Potter

\section{REFERÊNCIASBIBLIOGRÁFICAS}

Adorno, Theodor W. \& Horkheimer, Max. (1985) Dialética do esclarecimento (fragmentos filosóficos). Rio de Janeiro, Jorge Zahar Editor.

Castoriadis, Cornelius. (1982) A instituição imaginária da sociedade. Rio de Janeiro, Paz \& Terra.

Chevalier, Jean \& Gheerbrant, Alain. (1988) Dicionário de Símbolos. Rio de Janeiro, José Olympio.

GAY, Peter. (1988) A educação dos sentidos (a experiência burguesa, da Rainha Vitória a Freud). São Paulo, Companhia das Letras.

Hegel, George Wilhelm Friedrich. (1984) Filosofia real. México, Fondo de Cultura Económica.

MARcuse, Herbert. (1981) Eros e civilização. Rio de Janeiro, Zahar Editores. . (1967) A ideologia da sociedade industrial. Rio de Janeiro, Zahar Editores.

RouAnet, Sérgio Paulo. (1988) Razão e Paixão. In: CARdoso, Sérgio et alii. Os sentidos da paixão. São Paulo, Companhia das Letras.

TöNNIEs, Ferdinand. (1979) Comunidad y sociedad. Buenos Aires, Losada.

Weber, Max. (1967) A ética protestante e o espírito do capitalismo. São Paulo, Pioneira.

Woolf, Virginia. (1993) Orlando. Barcelona, Editorial Lumen. 